\title{
Abnormalities of Growth and ICD-10 Coding
}

Scott D. Duncan, MD, MHA

International Classification of Diseases (I.C.D.) has evolved across decades, emerging from a death registry to a statistical classification system recognized within international healthcare systems. In the United States, the I.C.D. is used to statistically map mortality, health conditions, patient outcomes, and reimbursement. While most historians would recognize Jacques Bertillon, Chief of Statistics for the City of Paris, as the father of the modern I.C.D. system, attempts at disease classification extend as far back as the $15^{\text {th }}$ century, and includes British epidemiologist William Farr's classification for statistical purposes, appearing in the First Annual Report of the Registrar - General of Births, Deaths, and Marriages in England, 1837-38.1,2 By 1893, Bertillon presented his classification system, focusing on anatomical sites, which was published as the International List of Causes of Death. ${ }^{1}$ The I.C.D. system has been revised and/or expanded to include causes of death, illnesses, and injuries. A list of revisions may be found in Table 1.

"While the I.C.D. system introduced prematurity as a cause of death as early as ICD-1, ICD-7 introduced specific conditions with and without mention of immaturity. ${ }^{3}$ ICD-9 introduced three general categories of related to fetal growth and gestation including 1) slow fetal growth and fetal malnutrition, 2) disorders relating to short gestation and low birthweight and 3) disorder relating to long gestation and high birthweight. ${ }^{4 "}$

While the I.C.D. system introduced prematurity as a cause of death as early as ICD-1, ICD-7 introduced specific conditions with and without mention of immaturity. ${ }^{3}$ ICD-9 introduced three general categories of related to fetal growth and gestation including 1) slow fetal growth and fetal malnutrition, 2) disorders relating to short gestation and low birthweight and 3 ) disorder relating to long gestation and high birthweight. ${ }^{4}$ Within the group of infants demonstrating slow fetal growth and fetal malnutrition, subcategories included light for dates infants without mention of malnutrition (i.e., infants underweight for gestational age, light for dates infants with signs of fetal malnutrition (i.e., infants underweight for gestation age and showing signs of malnutrition), fetal malnutrition without mention of light for dates (i.e., infants who are not underweight for gestational age, but are showing signs of malnutrition), and a category labelled fetal growth retardation, unspecified, which applies to intrauterine growth retarded infants. Within the category of disorders relating to short gestation and low birthweight, ICD-9 included subcategories of disorders relating to extreme immaturity of the infant, defined as a birthweight of less than 1,000 grams, but included birthweight exceeding 1,000 grams. ICD-9 also introduced a subcategory of preterm infants, defined as a birthweight of 1,000-2,500 grams, but included birthweights ranging from less than 1,000 grams to greater than 2,500 grams. Gestational age was introduced, with stratification from less than 24 weeks gestational age to 37 or more weeks gestational age, meant to be coded with birthweight, as appropriate. Those infants with long gestation and high birth weights were divided into infants with a birthweight of 4,500 grams or more, large for gestation, born between 40-42 weeks or over 42 weeks.

With I.C.D. 10 came a reorganization of the classifications, while providing room for expansion, without disturbing the code structure. Within the area of fetal growth and gestation, ICD-10 better defined these subcategories, while maintaining the general categories noted previously. Found within the alphanumeric chapter "P," "Certain conditions originating in the perinatal period," P05-P08 encompasses the diagnosis of the newborn related to the length of gestation and fetal growth. ${ }^{5}$ The general categories described in ICD-9 are found within P05, P07, and P08, respectively. The subcategories in P05 include P05.0X, newborn light for gestational age including birthweight less than $10^{\text {th }}$ percentile but length above $10^{\text {th }}$ percentile, subdivided by birthweight; P05.1X, newborn small for gestational age with birthweight and length both below $10^{\text {th }}$ percentile for gestational age, subdivided by birthweight; P05.2 newborn affected by fetal malnutrition not light or small for gestational age, and P05.9 newborn affected by slow intrauterine growth, i.e., IUGR.

Table 1

\section{I.C.D. Revisions ${ }^{3}$}

\begin{tabular}{|c|c|c|c|}
\hline Name & $\begin{array}{c}\text { Revi- } \\
\text { sion }\end{array}$ & Year & In Use \\
\hline $\begin{array}{c}\text { International List } \\
\text { of Causes of Death }\end{array}$ & First & 1900 & $1900-1909$ \\
\hline ILCD & Second & 1909 & $1910-1920$ \\
\hline ILCD & Third & 1920 & $1921-1929$ \\
\hline ILCD & Fourth & 1929 & $1930-1938$ \\
\hline ILCD & Fifth & 1938 & $1939-1948$ \\
\hline $\begin{array}{c}\text { International Clas- } \\
\text { sification of Dis- } \\
\text { eases, Injuries, and } \\
\text { Causes of Death }\end{array}$ & Sixth & 1948 & $1949-1957$ \\
\hline ICD & Seventh & 1955 & $1958-1967$ \\
\hline ICD & Eighth & 1965 & $1968-1978$ \\
\hline ICD & Ninth & 1975 & $1979-1994$ \\
\hline ICD & Tenth & 1989 & 1995 -present \\
\hline
\end{tabular}

Subcategories found within P07 include those related to short gestation and low birthweight. ICD-10 corrects the birthweight stratification, with codes P07.0X those infants of extremely low birthweight, 999 grams or less, regardless of gestational age, and P07.1X those newborns with a birth weight of 1,000-2,499 grams, regardless of gestational age and both sets excluding codes found in P05. P07.2X and P07.3X refer to extremely immature newborn (less than 23 weeks to 27 weeks) and the premature newborn (28 
weeks to 36 weeks), respectively.

P08 maintains the subcategories of exceptionally large newborn (P08.0, birthweight 4,500 grams or more, excluding I.D.M.), other heavy for gestational age newborn (P08.1, Large for Gestational Age, usually 4,000-4,499 grams, excluding I.D.M.) and the postterm newborn (P08.21 40-42 weeks) or prolonged gestation newborn (P08.22, gestation over 42 weeks).

In I.C.D. coding for the neonatologist, birthweight and gestational age remain an important distinction, as several E.M.R. data dictionaries mistakenly connect birthweight and gestational age together under a single code, for example, the infant described as "prematurity 500-749 grams, 25-26 complete weeks" as P07.02. When both birth weight and gestational age are available, proper I.C.D. coding dictates that both should be coded, with birthweight coded in sequence before gestational age. Further, the provider should be able to distinguish the proper codes for the infant that is small for gestation by weight, weight, and length, or of low birthweight regardless of gestational age.

Reimbursement in neonatology is based upon proper documentation, supporting the Current Procedural Terminology (CPT®) and International Classification of Disease, Tenth Revision, Clinical Modification codes. Many practices required the neonatologist and/or advanced practice provider (APP) to select the correct diagnosis, which may impact payments to the provider and healthcare system. The neonatal care practitioner should have knowledge of correct diagnosis coding, selecting the correct code(s) for the neonate.

\section{Questions}

1. A $243 / 7$ weeks gestational age male neonate with a birthweight of 650 grams and a length of $31 \mathrm{~cm}$ is admitted to the NICU. The correct ICD-10 code(s) for this patient would include:
A. P05.02
B. $\mathrm{P} 07.02$
C. P07.23
D. $\mathrm{P} 05.12$

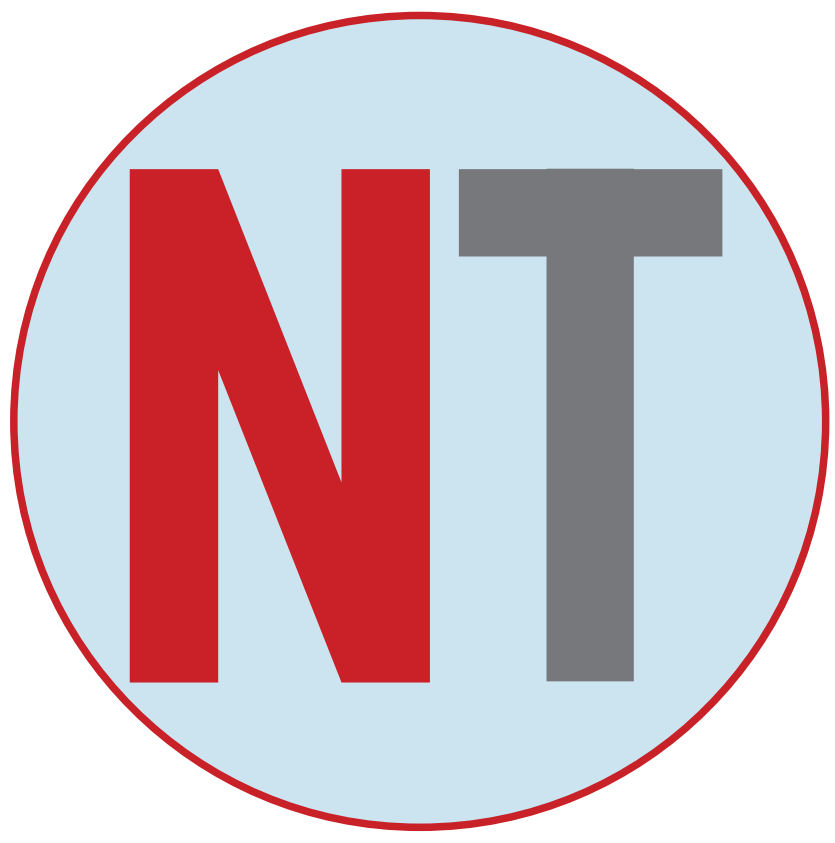

The correct answers are B and C.

P07.02 represents an extremely low birthweight infant of 500-749 grams.

P07.23 represents an extremely immature infant of 24 completed weeks gestation

2. A $243 / 7$ weeks gestational age male neonate with a birthweight of 490 grams and a length of $29.5 \mathrm{~cm}$ is admitted to the NICU. The correct ICD-10 code(s) for this patient would include:
A. P05.01
B. P07.01
C. P07.23
D. P05.11

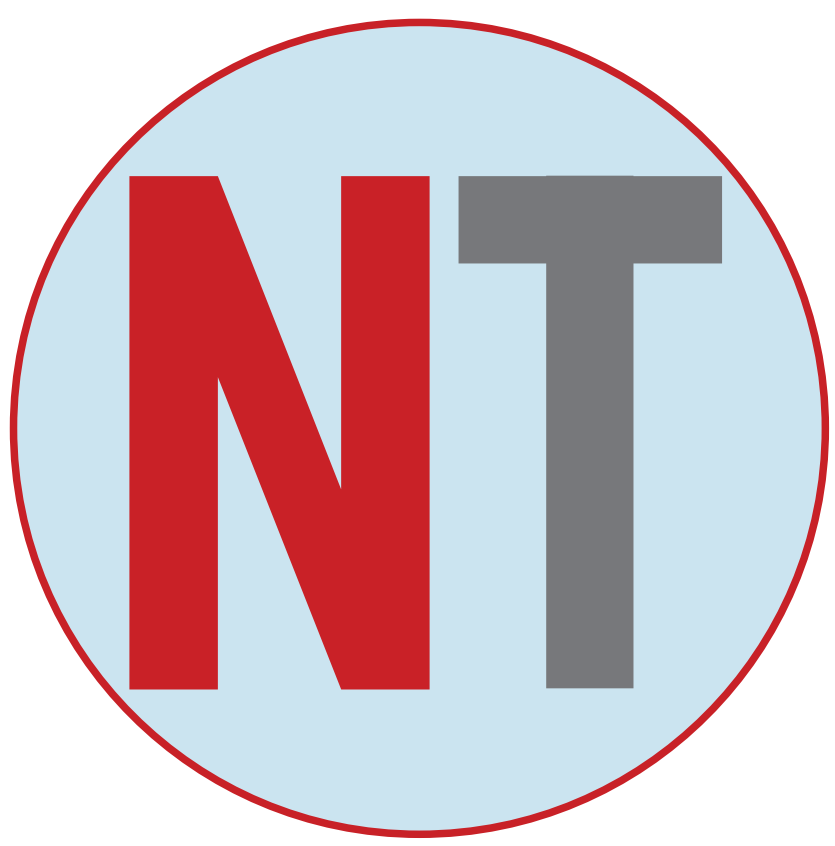

The correct answers are $\mathrm{A}$ and $\mathrm{C}$.

P05.01 represents light for dates infant with a weight of less than 500 grams, less than the $10^{\text {th }}$ percentile, but a length above the $10^{\text {th }}$ percentile.

P07.23 represents an extremely immature infant of 24 completed weeks gestation

\section{References:}

1. Moriyama IM, Loy RM, Robb-Smith AHT, Rosenberg HM, Hoyert DL, National Center for Health Statistics (U.S.). History of the statistical classification of diseases and causes of death. Hyattsville, Md.: U.S. Department of Health and Human Services, Centers for Disease Control and Prevention, National Center for Health Statistics; 2011.

2. Eyler JM. Victorian social medicine: the ideas and methods of William Farr. Baltimore: Johns Hopkins University Press; 1979.

3. International Classification of Diseases. Wolfbane Cybernetic Ltd.. wolfbane.com/icd/index.html. Accessed July 13, 2020.

4. ICD9Data.com.http://www.icd9data.com/2015/Volume1/760-779/764-779/default.htm. Accessed July 13, 
5. ICD10Data.com.https://www.icd10data.com/ICD10CM/ Codes/P00-P96/P05-P08. Accessed July 13, 2020.

Disclosure: The author has no disclosures.

NT
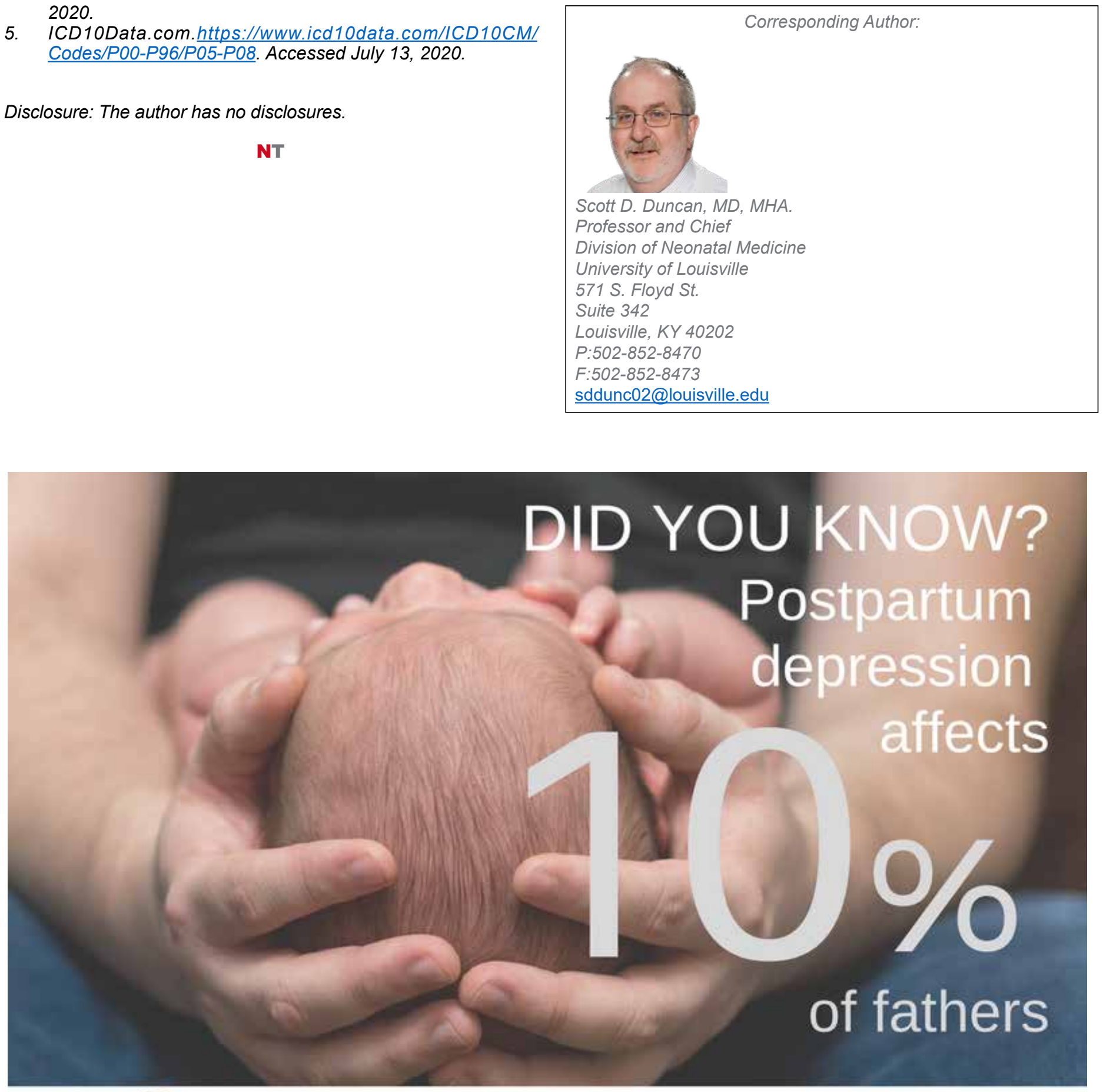

\section{Join O NPA}

www.nationalperinatal.org/mental_health

NEONATOLOGY TODAY is interested in publishing manuscripts from Neonatologists, Fellows, NNPs and those involved in caring for neonates on case studies, research results, hospital news, meeting announcements, and other pertinent topics.

Please submit your manuscript to: LomaLindaPublishingCompany@gmail.com 